\title{
Identification and fine mapping of a novel qGR6.2 locus controlling rice salt tolerance during seed germination
}

\section{Peng Zeng}

Nanjing Agricultural University

\section{Peiwen Zhu}

Nanjing Agricultural University

Luofeng Qian

Nanjing Agricultural University

Zefeng Lin

Nanjing Agricultural University

Xumei Qian

Nanjing Agricultural University

Yuxin Mi

Nanjing Agricultural University

Shinan Dong

Nanjing Agricultural University

Henrik Aronsson

Goteborgs Universitet

Hongsheng Zhang

Nanjing Agricultural University

Jinping Cheng ( $\nabla$ cjp@njau.edu.cn )

Nanjing Agricultural University https://orcid.org/0000-0002-7519-6517

\section{Original article}

Keywords: Rice, Salt tolerance, Seed germination, Quantitative trait loci (QTLs), Fine mapping, Markerassisted selection (MAS)

Posted Date: January 28th, 2020

DOI: https://doi.org/10.21203/rs.2.22040/v1

License: (c) (i) This work is licensed under a Creative Commons Attribution 4.0 International License. Read Full License 


\section{Abstract}

The rice growth is strongly affected by salt stress. When exposed to high salt stress, seed germination and seedling establishment are significantly inhibited. Particularly, with the promotion of rice directseeding technology in Asia, improving rice salt tolerance during seed germination is of great importance for rice breeding. In this study, an indica rice landrace Wujiaozhan (WJZ) showed significant salt tolerance during seed germination. The dynamic process of seed germination at $300 \mathrm{mM} \mathrm{NaCl}$ was observed via the germination rate (GR), seedling percentage (SP), and germination index (GI) from the progeny by crossing WJZ with the salt-sensitive Nipponbare (Nip). By QTL mapping, sixteen quantitative trait loci (QTLs) related to salt-tolerance were detected via a BC1F2 population, including six QTLs for the GR, eight QTLs for the SP, and two QTLs for the GI. Of them, four

QTLs, qGR6.1, qGR6.2, qGR10 and qSP10.1, were expressed continuously, especially qGR6.2 and qGR10. Furthermore, twelve significant associated simple sequence repeats (SSR) markers were detected in the F2 population by bulked segregant analysis (BSA). Four SSR markers (RM588, RM190, RM276 and RM5493) were closed to qGR6.1, qGR6.2, qGR6.3, qSP6.1, qSP6.2, qGI6 and qSP8.1 identified by QTL mapping. The major qGR6.2 on chromosome 6 was confirmed via the BC2F2 population, which explained more than $20 \%$ phenotype variation of the GR. Fine mapping results displayed that qGR6.2 was narrowed down to a $65.9 \mathrm{~kb}$ region between the Z654 and Z619 markers, with eleven candidate genes predicted. Based on the microarray database, six genes (LOC_Os06g10650, LOC_Os06g10660, LOC_Os06g10690, LOC_Os06g10710, LOC_Os06g10730 and LOC_Os06g10750) were differentially expressed after seed imbibition or salt stress. RT-qPCR showed that two genes (LOC_Os06g10650 and LOC_Os06g10750) were significantly induced by salt stress and had different expression patterns in two parents during seed germination.

\section{Background}

Soil salinity is the primary abiotic stress affecting crop growth and productivity worldwide (Zhu 2001). It is estimated that $6 \%$ of the earth's landmass and $20 \%$ of irrigated land are affected by salinity (Munns and Tester 2008). Rice is the most important staple food, feeding more than half of the world's population. Compared to wheat and cotton, rice is more sensitive to salt stress, and approximately $30 \%$ of the rice-growing area in the world is affected by salinity (Takehisa et al. 2004). According to the previous reports, high salinity inhibits seed germination and seedling establishment, reduces plant growth and diminishes rice yield (Wang et al. 2011; Kumar et al. 2013). Although saline soils could be improved by large-scale irrigation, drainage schemes and chemical treatment, all these solutions are too costly (Munns and Gilliham. 2015). Hence, genetic improvement of salt tolerance has been an important and feasible objective for rice breeding in coastal areas.

To dissect the genomic regions associated with target traits in the crops, a number of technologies are available, including QTL (quantitative trait locus) mapping (Li et al. 2011; Zhang et al. 2012), BSA (bulked segregant analysis) mapping (Salunkhe et al. 2011; Vikram et al. 2012), and genome-wide association analysis (GWAS) (Huang et al. 2010; Han and Huang 2013). QTL mapping and BSA mapping are both 
based on linkage analysis. QTL mapping may provide the basis for map-based cloning of genes and MAS (marker-assisted selection) (Tiwari, et al 2016). BSA mapping is often used to identify the major effective QTLs with linkage marker in a shortcut and effective way (Michelmoore et al. 1991). Multiple approaches were also applied together to identify the target QTLs. Zheng et al. (2015) reported seven QTLs for $\mathrm{Na}^{+}$and $\mathrm{K}^{+}$concentrations using linkage mapping and association mapping. Lai et al. (2016) found ten additive QTLs of seed vigor, which could be stably identified for 2 years through QTL Cartographer, QTL Network program and BSA methods.

Salt tolerance is a polygenic characteristic highly influenced by the environment and multiple genes (Johnson et al. 1992; Wang et al. 2012b), which makes it difficult to identify the QTLs and genes. Up to now, more than hundreds of salt-response QTLs have been reported at different developmental growth stages in rice (Ganie et al. 2019). Salt tolerance during seed germination is not consistently related to other stages, such as vegetative growth or fruit development (Johnson et al. 1992, Shi et al. 2017). So far, few studies aimed at salt tolerance during seed germination in rice. Wang et al. (2011) detected 16 QTLs of rice seed germination ability from the salt tolerance variety Jiucaiqing at $100 \mathrm{mM} \mathrm{NaCl}$. Recently, around 50 salt tolerance loci have been identified using GWAS at the seed germination stage (Cheng et al. 2015; Shi et al. 2017; Yu et al. 2018). Fujino et al. (2008) reported that qLTG3-1 responded to seed germination under salt stress because of tissue vacuolation and weakening. Recently, a potassium transport OsHAK21 (He et al. 2019) was reported to mediate salt tolerance at the seed germination stage by involving in abscisic acid (ABA) metabolism. However, it is still limited genes or QTLs to reveal the genetic mechanisms of salt tolerance during seed germination in rice.

In this study, an indica rice variety Wujiaozhan (WJZ) from 276 indica accessions (Cheng et al. 2015) was identified as high salt tolerance during seed germination. Salt tolerance at the seed germination stage was evaluated by the traits of GR (germination rate), SP (seedling percentage) and GI (germination index). QTL mapping and BSA (bulked segregant analysis) were developed to excavate QTLs by the progeny derived from WJZ and the salt-sensitive japonica rice variety Nipponbare (Nip) at $300 \mathrm{mM} \mathrm{NaCl}$. Consequently, a major QTL qGR6.2 on the short arm of chromosome 6 could be detected among several generations, and finally fine mapped to a $65.9 \mathrm{~kb}$ region between the two markers Z654 and Z619. Our work is beneficial to better understand the genetic and molecular basis of salt tolerance during seed germination.

\section{Results}

\section{Salt tolerance of two parents during seed germination}

There were no differences in germination rate (GR) and seedling percentage (SP) between salt-sensitive variety Nip and salt-tolerance WJZ at $0 \mathrm{mM} \mathrm{NaCl}\left(\right.$ or $\mathrm{H}_{2} \mathrm{O}$ ) imbibition for ten days (Fig. 1a,1b). Under $\mathrm{NaCl}$ stress conditions, the GR and SP of WJZ were significantly higher than those of Nip, especially at 300 $\mathrm{mM} \mathrm{NaCl}$ imbibition (Fig. 1a, 1b). There was significantly higher germination index (GI) of WJZ under $\mathrm{H}_{2} \mathrm{O}$ or $\mathrm{NaCl}$ imbibitions (Fig. 1c). It indicated that WJZ was more salt-tolerant at the seed germination stage. 
Since there was an irreparable injury for the seedlings at $350 \mathrm{mM} \mathrm{NaCl}$, the SP of WJZ and Nip was $23.33 \%$ and $0.00 \%$ respectively (Fig. 1 b). The seed germination was assessed with $300 \mathrm{mM} \mathrm{NaCl}$ for further analyses.

At $300 \mathrm{mM} \mathrm{NaCl}$, the significant differences in GR were observed between WJZ and Nip from 3 to 14 days during seed germination (Fig. 1d, 1e). The WJZ started to germinate after imbibition for 3 days and its GR reached to $90 \%$ after 7 days (Fig 1e). After imbibition for 14 days, WJZ presented a higher GR of $95.55 \%$, while Nip only $34.44 \%$.

\section{QTL mapping combined with BSA identify salt tolerance loci during seed germination}

To identify QTLs related with salt tolerance during seed germination, a $\mathrm{BC}_{1} \mathrm{~F}_{1}$ line containing about $37.76 \%$ genetic region of Nip was used to generate a $\mathrm{BC}_{1} \mathrm{~F}_{2}$ population (Fig. S1). It was analyzed that the $\mathrm{GR}, \mathrm{SP}$ and $\mathrm{GI}$ of the $\mathrm{BC}_{1} \mathrm{~F}_{2}$ population (181 lines) from from 4 to 14 days (Fig. S2, S3). The dynamic distributions of GR and SP of this population under salt stress could be classified into two categories during seed germination, symmetrical distribution and skewed distribution (Fig. S2, S3). It showed a skewed distribution for GR at the beginning of seed germination ( $4 \sim 6$ days) and the end of seed germination ( $9 \sim 14$ days) (Fig. S2a-c, f-k), while a symmetrical distribution at the day 7 and (Fig. S2d, e). Besides the two parents, these 181 lines also had a large variation of GR on days 7, 8, 9, ranging from 0 to $100 \%$ (Fig. S2d-f). It indicated that this population had a large genetic diversity. Similar results were observed from the SP of this population. On day 11 the symmetrical distribution was observed, whereas from 7 to 10 days a positively skewed distribution was apparent, and from 11 to 14 days a negatively skewed distribution appeared (Fig. S3a-h).

A molecular linkage map consisting of 203 simple sequence repeat (SSR) or InDel (Insertion/Deletion) markers was constructed (Table S1). Sixteen QTLs related to salt tolerance during seed germination were identified on chromosome 1, 6, 7, 8, and 10 respectively (Table 1; Fig. 2), including six QTLs for the GR, eight for the SP, and two for the GI. The additive effects of these QTLs were negative, ranged from -0.04 to -12.13 (Table 1), suggesting that the positive alleles were derived from the salt-tolerant parent WJZ. Eight major QTLs, qGR1, qGR6.2, qGR8, qG/6, qG/10, qSP1, qSP6.2, and $q S P 10.1$ detected in this study could explain more than $20 \%$ of the variation respectively, and these could be the major QTLs. Interestingly, qGR1 and $q S P 1$ explained $72.22 \%$ and $62.27 \%$ of the phenotypic variation, respectively (Table 1). Five QTLs, qGR6.1, qGR6.2, qGR10, qSP6.1, and $q S P 10.1$ were detected the different times, including the qGR6.2 from 7 to 14 days, $q G R 10$ from 4 to 14 days, and $q S P 6.1$ and $q S P 10.1$ from 10 to 14 days (Fig. 2). By comparison, the $q G R 1$ was co-located with $q S P 1$ between RM8105 and $\mathrm{Y} 3$ region on chromosome 1, the $q G R 6.2$ co-located with $q S P 6.1$ and $q G / 6$ between $Z 64$ and RM276 region on chromosome 6 , the qGR6.3 co-located with $q S P 6.2$ between RM276 and RM7088 region on chromosome 6, the $q G R 8$ colocated with $q S P 8.1$ between RM3572 and RM6208 region on chromosome 8, the $q G R 10$ co-located with qSP10.1 and $q G / 10$ between W13 and W20 region on chromosome 10 (Table 1; Fig. 3). 
Additionally, the linkage markers of salt tolerance were also identified by bulked segregant analysis (BSA) in this study. Total 73 individual plants were selected and obtained for BSA as they had similar agronomic traits to Nip but shared a great variation of GR, SP and GI (Table S2). Of them, eight high salttolerant lines and eight salt-sensitive lines were applied for two extreme phenotype bulks (Fig. S4). A total of 12 SSR markers associated with salt tolerance at the seed germination stage were identified on chromosome 1, 3, 4, 5, 6, and 8 (Table 2; Fig. 3). Among them, RM3564 was adjacent to RM3684 on chromosome 3, RM588 was adjacent to RM190 on chromosome 6, suggesting that the adjacent markers might be the same loci. Compared with QTLs from the $\mathrm{BC}_{1} \mathrm{~F}_{2}$ population, two SSR markers RM588 and RM190 were close to $q G R 6.1$, the RM276 close to $q G R 6.2, q G R 6.3, q S P 6.1, q S P 6.2$ and $q G / 6$ (Table 2; Fig. $3)$, indicating these seven QTLs might be the key QTLs for salt tolerance during seed germination.

\section{Validation and fine mapping of $q G R 6.2$ for controlling salt tolerance during seed germination}

Based on QTL mapping and BSA, a major $q G R 6.2$ within the interval of Z604 RM276 was further confirmed. A significant peak was obtained between the markers $\mathrm{Z} 604$ and RM276 in the $\mathrm{BC}_{2} \mathrm{~F}_{2}$ population and accounted for $20.96 \%$ and $23.53 \%$ of the GR variation at 12 th and 14 th day respectively (Fig. 4; Table S3). The genetic effect of $q G R 6.2$ was validated in different populations (Table 1, 2, S3; Fig. 2-4). These results indicated that $q G R 6.2$ was a major locus controlling salt tolerance during seed germination in rice.

To fine map the major-effective locus $q G R 6.2$, a larger $\mathrm{BC}_{2} \mathrm{~F}_{3}$ population comprising 1,205 individuals was developed. Total eighty-six recombinants were identified between Z604 and RM276. Eight polymorphic markers were developed within a wider interval between RM190 and RM3183, in case of possible shifting of the target locus (Fig. 5a). The progeny of recombinants was tested using these markers to identify homozygous individuals for the salt response during seed germination. Based on the genotypes, the 86 recombinants were classified into four groups. 18 recombinant events were between Z604 and Z616, 57 recombinant events between Z617 and Z619, and 11 between Z605 and RM276 (Fig. $5 b)$. The mean GR of homozygous WJZ alleles in group B and D was significantly higher than Nip alleles, while no difference in group $A$ and $C$. Therefore, the $q G R 6.2$ was delimited between the $Z 617$ and Z619 markers. In the same way, a larger $\mathrm{BC}_{2} \mathrm{~F}_{4}$ population derived from heterozygous $\mathrm{BC}_{2} \mathrm{~F}_{3}$ plants in marker Z617 and Z619 was conducted, containing 2,318 individuals. Seventeen recombinants were obtained, including three types of recombination (Fig. $5 \mathrm{c}$ ). Based on progenies assay of each recombinant, the qGR6.2 locus was finally narrowed down to a $65.9 \mathrm{~kb}$ region between the markers Z654 and Z619 (Fig. $5 c)$.

\section{Prediction and expression analysis of candidate genes in the $q G R 6.2$ locus}

According to the MSU Rice Genome Annotation Project Database (http://rice.plantbiology.msu.edu), eleven opening reading frames (ORFs) were annotated in the $q G R 6.2$ locus within $65.9 \mathrm{~kb}$ region, including five functional proteins, one transposon protein and five expressed proteins without annotation (Table 3). Gene function annotation showed that the ORF1 (LOC_OsO6g10650) encodes a tyrosine 
phosphatase (TPT) family protein, ORF2 (LOC_Os06g10660) a lysM domain-containing GPI-anchored protein 1 precursor, ORF3 (LOC_Os06g10670) aspartic proteinase nepenthesin-1 precursor, ORF5 (LOC_Os06g10690) PHD-finger domain containing protein, and ORF11 (LOC_Os06g10750) an integral membrane protein DUF6 containing protein.

Meanwhile, the expression profiles of these candidate genes were conducted in various developmental stages囚incubation of seed imbibition and salt stress based on mRNASeq data and Array database deposited in the GENEVESTIGATOR (Fig. 6). The higher transcript abundances of seven genes ORF1 (LOC_Os06g10650), ORF2 (LOC_Os06g10660), ORF3 (LOC_Os06g10670), ORF5 (LOC_Os06g10690), ORF7 (LOC_OsO6g10710), ORF9 (LOC_Os06g10730)and ORF11 (LOC_Os06g10750) were observed at all of the developmental stages, while almost no expression for ORF4 (LOC_Os06g10680), ORF6 (LOC_Os06g10700) and ORF8 (LOC_Os06g10720)(Fig. 6a). During seed germination, the expression of ORF1 (LOC_Os06g10650) was significantly up-regulated by seed imbibition, and ORF7 (LOC_Os06g10710) was obviously down-regulated (Fig. 6b). Interestingly, only ORF11 (LOC_Os06g10750) showed significant down-regulated expression patterns when exposed to salt stress in root and seedling samples (Fig. 6b).

We subsequently conducted quantitative real-time PCR (RT-qPCR) analysis to detect the expression of these genes in WJZ and Nip during seed germination subjected to salt stress. It was found that the gene ORF1 (LOC_OSO6g10650) was dramatically induced by salt stress after imbibition for $24 \mathrm{~h}$, nearly 20 -fold change in WJZ and 14-fold in Nip (Fig. 7a). Eight genes, ORF3 (LOC_OsO6g10670), ORF4 (LOC_Os06g10680), ORF6 (LOC_Os06g10700), ORF7 (LOC_Os06g10710), ORF8 (LOC_Os06g10720), ORF9 (LOC_OsO6g10730), ORF10 (LOC_Os06g10740) and ORF11 (LOC_Os06g10750) showed downregulation of expression pattern during seed germination (Fig. 7). Comparing the expression level between two parents, we found ORF11 (LOC_Os06g10750) in Nip was nearly 10-fold higher than in WJZ (Fig. 7k).

\section{Discussion}

Salinity seriously affects rice seed germination and seedling establishment, especially in the directseeding area, leading to a reduction of rice yields (Wang et al. 2012b; Shi et al. 2017). In this study, the indica landrace WJZ from Yunnan province in China showed a strong capability of seed germination and seedling establishment under high salinity stress. Even when exposed to $300 \mathrm{mM} \mathrm{NaCl}$, visible seeds of WJZ could start to germinate after three days of imbibition and established normal seedlings after five days. It suggests that WJZ is an important germplasm source with strong salt tolerance during seed germination, similar to N22-334-3 (Kumar et al. 2013) and Jiucaiqing (He et al. 2019). However, WJZ was

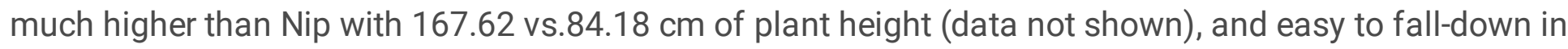
field planting. It is of great importance to explore elite genes controlling salt tolerance during seed germination from WJZ, which will be beneficial for improving rice salinity tolerance in the direct-sowing areas. 
Evaluating the phenotype of salt tolerance comprehensively and accurately is the most crucial step for QTL mapping (Wang et al. 2012a). To estimate the dynamic characteristics of salt tolerance during seed germination, three germination-related traits (GR SP, and GI) at $300 \mathrm{mM} \mathrm{NaCl}$ were recorded in this study. During seed germination, the dynamic distribution characteristics of the $\mathrm{BC}_{1} \mathrm{~F}_{2}$ population transformed positively skewed distribution (4 to 6 days for GR, 7 to 10 days for SP) into negatively skewed distribution (8 to 14 days for GR, 12 to 14 days for SP). Obviously, seed germination was delayed by salt stress, leading to impaired seedling establishment. Besides, the symmetrical distributions were showed at GR of 7th day, SP of 11th day, where most of the seeds started to germinate and establish seedlings, respectively. These results suggested that there were large variations at different germination stages, and salt tolerance during seed germination is a quantitative trait regulated by multiple genetic mechanisms.

In this study, a total of 16 QTLs and 12 linkage markers controlling salt tolerance during seed germination were identified via QTL mapping and BSA mapping. The comparison revealed that seven QTLs (qGR6.1, qGR6.2, qGR6.3, qSP6.1, qSP6.2, qGI6 and qSP8.2) in the $\mathrm{BC}_{1} \mathrm{~F}_{2}$ population were co-localized with linkage markers in the $F_{2}$ population. The coincidence indicated that these QTLs identified by QTL mapping and BSA might be the key QTLs for salt tolerance during rice seed germination. In addition, nine QTLs were not identified nearby linkage markers via BSA mapping. This might be due to the different genetic background between the $F_{2}$ and $B_{1} F_{2}$ populations. Simultaneously, these co-localized loci being stably expressed via multiple generations could contribute to increasing salt tolerance during seed germination via the marker-assisted breeding program.

Until now, many studies have been exploring QTLs for salt stress in rice. By comparing chromosomal locations, eleven QTLs in our study were located in the same or adjacent regions with previous reported QTLs. The linkage markers RM128, RM1164, RM3436, and RM480 in the $F_{2}$ population were located near the region of qSSIGY1.1, qSSIGY3.3, qSSIGY3.7, qSSIGY5.2 and qSSIGY5.5 for seedling salt tolerance respectively (Tiwari et al. 2016). The region of qGR10, qSP10, and qGI10 in the $\mathrm{BC}_{1} \mathrm{~F}_{2}$ population were similar to qSKC10 and qRKC10 for seedling salt stress (Wang et al. 2012a). There is a gene OsRR22 located within the region of qGR6.2, qSP6.1, and qGI6, which controlling salt stress at the seedling stage (Takagi et al. 2015). Similar results were found for RM588 and RM190 with OsDREB1C (Dubouzet et al. 2003), and for qGR1 and qSP1 with OsSKC1 (Ren et al. 2005). It indicated these co-localized QTLs at the different developmental stages were the weightily genomic regions for salt tolerance in rice. In addition, the other five mapped QTLs (qSP7, qSP8.1, qSP8.2, qGR8 and qSP10.2) in this study are novel alleles with no previous reports of salt tolerance in rice.

Interestingly, the major qGR6.2 was identified via multiple mapping methods and expressed continuously, with a relatively higher contribution and additive effects at $300 \mathrm{mM} \mathrm{NaCl}$ during seed germination. With validation in the $\mathrm{BC}_{2} \mathrm{~F}_{2}$ population and fine-mapping strategy, qGR6.2 was finally mapped in a region of $65.9 \mathrm{~kb}$ between the two markers Z654 and Z619. A total of 11 candidate genes in the Nipponbare genome were predicted. Of these genes, we found that LOC_Os06g10650 encoded tyrosine phosphatase (TPT) family protein and LOC_Os06g10750 encoded integral membrane protein DUF6 containing protein 
with differentially expressed by seed imbibition or exposure of salt stress based on mRNASeq data. According to the previous studies, TPT family protein has been reported to regulate signal transduction and control plant growth and development (Stoker, 2005). AtPTP1 encoding a putative protein tyrosine phosphatase (PTPase), the first TPT family gene in plant was upregulated by high salt stress (Xu et at. 1998). An integral membrane protein DUF6 containing protein At01g09380 was involved in salt stress and drought stress (Sun et al. 2009). Furthermore, the different expression patterns of these two genes from RT-qPCR were also observed in WJZ and Nip after seed imbibition at $300 \mathrm{mM} \mathrm{NaCl}$, suggesting the different roles of them in two parents. All these indicated that LOC_Os06g10650 and LOC_Os06g10750 might be the casual candidate genes responding to salt tolerance during seed germination. More experiments should be performed to validate the functions of these candidate genes.

In summary, we fine mapped a novel major QTL qGR6.2 for salt tolerance during seed germination within a region of $65.9 \mathrm{~kb}$ and identified two more likely candidate genes, LOC_Os06g10650 and LOC_Os06g10750. Sequence analysis and genetic transformation will be carried out in the future to validate the candidate genes and elucidate the molecular mechanism underlying salt tolerance at the seed germination stage. We believe that the major QTL qGR6.2 is useful for improving salt tolerance by the MAS strategy.

\section{Materials And Methods}

\section{Plant materials}

Two rice varieties, the high salt-tolerant indica Wujiaozhan (WJZ) and the salt-sensitive japonica Nipponbare (Nip), and their $F_{2}, B C_{1} F_{2 ~ 4}$, populations were used in this study. The $B_{1} F_{2}$ and $B_{2} F_{2}$ were developed for QTL mapping and the $F_{2}$ population was for BSA (Fig. S1). All plants were grown in a paddy field at the Jiangpu Experimental Station (Jiangsu Province, China) in 2014, 2015, 2016, 2017 and 2018 , with $17 \mathrm{~cm}$ between plants within a row and $33 \mathrm{~cm}$ between rows. Seeds of each line were harvested at maturity and dried at $42{ }^{\circ} \mathrm{C}$ for 7 days to break seed dormancy, and then stored at $-20{ }^{\circ} \mathrm{C}$.

\section{Evaluation of seed tolerance during seed germination}

A total of 30 healthy grains of each accession were surface-sterilized with $0.5 \%$ sodium hypochlorite solution for $15 \mathrm{~min}$ and then rinsed three times with sterile distilled water. Seeds were imbibed in $9 \mathrm{~cm}$ Petri dishes with $40 \mathrm{~mL}$ quartz and $20 \mathrm{~mL}$ solution, with normal (sterile distilled water), and salt conditions $(150 \mathrm{mM}, 200 \mathrm{mM}, 250 \mathrm{mM}, 300 \mathrm{mM}, 350 \mathrm{mM} \mathrm{NaCl})$ at $25 \pm 1{ }^{\circ} \mathrm{Cfor} 14$ days in a growth chamber under $12 \mathrm{~h}$ light/12 $\mathrm{h}$ day conditions. Seed germination was defined as the emergence of the radicle $(2 \mathrm{~mm}$ ) through the surrounding tissue, and the seedling establishment was considered when the root length reached the seed length and the shoot length reached half of the seed length (Cheng et al. 2015). Germination rate (GR) and seedling percentage (SP) were calculated on a daily basis. Germination index $(\mathrm{GI})$ was calculated as $\mathrm{GI}=\sum(G t / \mathrm{t})$, where $G t$ is the number of germinated seeds on day $t$ (Wang et al. 2011). Three replications of each line were performed. 


\section{DNA extraction and PCR analysis}

Total genomic DNA was extracted from young leaves of each individual plant using the cetyltrimethylammonium bromide (CTAB) method. According to the International Rice Microsatellite Initiative (IRMI, http://www.gramene.org) (MoCouch et al. 2002), a total of 287 SSR markers were revealed polymorphisms between WJZ and Nip and scattered on 12 chromosomes with an average interval of $\sim 10 \mathrm{cM}$ (Table S1). PCR was performed as described by Chen et al. (1997). The PCR products were separated by electrophoresis through $8 \%$ non-denaturing polyacrylamide gels and visualized by silver staining.

\section{BSA analysis and QTL mapping}

A total of 73 plants with similar agronomic characters as Nip were selected from the $3,000 \mathrm{~F}_{2}$ progeny for BSA (Table S2). Among them, two extreme phenotypes bulks were selected to determine the linkage markers with salt tolerance, including salt-tolerant bulk with simultaneously higher GP, SP, and GI and sensitive bulk with lower GP, GR, and GI (Fig. S4). Primary genetic map construction was performed with 181 individuals from the $\mathrm{BC}_{1} \mathrm{~F}_{2}$ population by Mapmaker/Exp 3.0 (Lander et al. 1987). QTL analysis was carried by Inclusive Composite Interval Mapping (ICIM) (Li et al. 2008) with a threshold of LOD $₫ 2.5$ operating 1000 permutations. The phenotypic variance, additive and dominance effects of each QTL were estimated.

\section{Confirmation and fine mapping of $q G R 6.2$}

To ensure the presence of the major QTL qGR6.2, a linkage map of 70 individuals from $\mathrm{BC}_{2} \mathrm{~F}_{2}$ progeny were analyzed with 11 SSR markers on chromosome 6 (Table. S4). Another ten polymorphic InDel markers were explored and used for fine mapping. In this study, $1205 \mathrm{BC}_{2} \mathrm{~F}_{3}$ and $2318 \mathrm{BC}_{2} \mathrm{~F}_{4}$ plants were used for fine mapping the target QTL qGR6.2. To determine the location of more precisely, totally seven types of recombinants from the $\mathrm{BC}_{2} \mathrm{~F}_{3 \sim 4}$ segregating populations were identified. Twenty progenies of each recombinant were planted in a two-row plot with 10 individuals in each row, and the homozygous plants were selected for the seed germination test.

\section{Prediction and expression analysis of candidate genes}

Open reading frames (ORFs) in the region of markers Z654 and Z619 were predicted by Rice Annotation Project Database (http://rice.plantbiology.msu.edu/). The GENEVESTIGATOR (https://genevestigator.com/gv/) was employed to analyze the expression patterns of eleven candidate genes based on 2836 Affymetrix microarray datasets and 986 mRNASeq data with a significant level $\mathrm{P}<$ 0.05 in seed imbibition and salt stress.

Seeds of two parents were sampled after $0 \mathrm{~h}, 6 \mathrm{~h}, 12 \mathrm{~h}, 24 \mathrm{~h}, 36 \mathrm{~h}$ and $48 \mathrm{~h}$ imbibition at $300 \mathrm{mM} \mathrm{NaCl}$, and then frozen quickly in liquid nitrogen and stored at $-80{ }^{\circ} \mathrm{C}$ for RNA extraction. Total RNA was isolated from approximately 80 100 mg powder with Total RNA Kit (BioTeke, http://www.bioteke.com). The first- 
strand cDNA was synthesized with random oligonucleotides using the HiScript II Reverse kit (Vazyme Biotech, http://www.vazyme.com/) according to the manufacturer's protocol. To measure the mRNA levels of genes, quantitative real-time PCR (RT-qPCR) was conducted by CFX96 Real-time System (BIORAD, USA) with SYBR Green Mix (Vazyme). The rice housekeeping gene OsActin (LOC_Os03g50885) was used as an internal control. PCR conditions were as follows: $95^{\circ} \mathrm{C}$ for $5 \mathrm{~min}$, followed by 40 cycles of 95 ${ }^{\circ} \mathrm{C}$ for $15 \mathrm{~s}$ and $60{ }^{\circ} \mathrm{C}$ for $30 \mathrm{~s}$. A final melt curve stage of $65-95^{\circ} \mathrm{C}$ was performed to confirm the specificity of primer. Relative quantification of the transcript levels was obtained based on the $2^{-\Delta \Delta \mathrm{CT}}$ method (Livak and Schmittgen 2001). The amount of the transcripts in the WJZ after imbibing for $0 \mathrm{~h}$ was set at 1.0. All of the primers used for RT-qPCR were designed according to http://quantprime.mpimpgolm.mpg.de/ (Table. S5). Three biological replicates were conducted.

\section{Data analysis}

The experimental data were analyzed using the Statistical Analysis System (SAS) software (Cary, NC, USA), and compared with Student's $t$-test at the $5 \%$ and $1 \%$ levels of probability.

\section{Conclusions}

In our study, we identified 16 QTLs and 12 associated SSR markers conferring salt tolerance from indica landrace WJZ during seed germination, and the major qGR6.2 was fine mapped to a $65.9 \mathrm{~kb}$ region flanked by marker Z654 and Z619. Our results provide new information on the genetic basis of improving salt tolerance during seed germination by marker-assisted selection.

\section{Abbreviations}

WJZ: Wujiaozhan; Nip: Nipponbare; GR: Germination rate; SP: Seedling percentage; Gl: Germination index; QTLs: Quantitative trait loci; BSA: Bulked segregant analysis; MAS: Marker-assisted selection; SSR: Simple sequence repeats; InDel: Insertion/Deletion; ORF: Opening reading frame; TPT: Tyrosine phosphatase family protein; CTAB: Cetyltrimethylammonium bromide; MAS: marker-assisted selection; GWAS: genome-wide association analysis; ABA: abscisic acid; RT-qPCR: quantitative real-time PCR

\section{Declarations}

\section{Ethics approval and consent to participate}

Not applicable.

\section{Consent for publication}

Not applicable. 


\section{Availability of supporting data}

The datasets supporting the conclusions of this article are provided within the article and its additional files.

\section{Competing interests}

The authors declare no conflict of interests.

\section{Funding}

This work was supported by the National Natural Science Foundation of China (Grant No. 31771757, 31601387), the Fundamental Research Funds for the Central Universities (Grant No. KJQN201727), and the National Science and Technology Support Program (2015BAD01B01-2).

\section{Authors' contributions}

JP Cheng, HS Zhang and P Zeng conceived the project and designed the research. P Zeng performed most of the experiments and analyzed data; PW Zhu performed salt tolerance identification for fine mapping, P Zeng, LF Qian and ZF Lin carried out constructing the genetic map, XM Qian, YX Mi, and SN Dong participated in developing plant populations. $\mathrm{P}$ Zeng and JP Cheng wrote the manuscript. $\mathrm{H}$ Aronsson provided technical assistance to English writing. JP Cheng and HS Zhang supervised and complemented the writing. All authors read and approved the final manuscript.

\section{Acknowledgments}

Not applicable.

\section{References}

Ashokkumar K, Raveendran M, Senthil N et al (2013) Isolation and characterization of altered root growth behavior and salinity tolerant mutants in rice. African J Biotechnol 12 (40): 5852-5859.

https://doi.org/10.5897/ajb2013.12880 
Chen X, Temnykh S, Xu Y et al (1997) Development of a microsatellite framework map providing genomewide coverage in rice (Oryza sativa L.). Theor Appl Genet 95(4):553-567.

https://doi.org/10.1007/s001220050596

Cheng J, He Y, Yang B et al (2015) Association mapping of seed germination and seedling growth at three conditions in indica rice (Oryza sativa L.). Euphytica 206(1):103-115. https://doi.org/10.1007/s10681015-1477-1

Dubouzet JG, Sakuma Y, Ito Y et al (2003) OsDREB genes in rice, Oryza sativa L., encode transcription activators that function in drought-, high-salt- and cold-responsive gene expression. Plant J 33: 751-763. https://doi.org/10.1046/j.1365-313X.2003.01661.x

Fujino K, Sekiguchi H, Matsuda Y et al (2008) Molecular identification of a major quantitative trait locus, qLTG3-1, controlling low-temperature germinability in rice. Proc Natl Acad Sci USA 105 (34): 1262312628. https://doi.org/10.1073/pnas.0805303105

Ganie SA, Molla KA, Henry RJ et al (2019) Advances in understanding salt tolerance in rice. Theor Appl Genet 132:851-870.

https://doi.org/10.1007/s00122-019-03301-8

Han B, Huang X (2013) Sequencing-based genome-wide association study in rice. Curr. Opin. Plant Biol. 16:133-138. http://doi.org/10.1016/j.pbi.2013.03.006

He Y, Yang B, He Y et al (2019) A quantitative trait locus, qSE3, promotes seed germination and seedling establishment under salinity stress in rice. Plant J 97:1089-1104. https://doi.org/10.1111/tpj.14181

Huang X, Wei X, Sang T et al (2010) Genome-wide association studies of 14 agronomic traits in rice landraces. Nat Genet. 42: 961-967. https://doi.org/10.1038/ng.695

Kumar MN, Jane WN, Verslues PE (2013) Role of the putative osmosensor Arabidopsis histidine kinase1 in dehydration avoidance and low-water- potential response. Plant Physiol 161:942-953. https://doi.org/10.1104/pp.112.209791

Johnson DW, Smith SE, Dobrenz AK (1992) Genetic and phenotypic relationships in response to $\mathrm{NaCl}$ at different developmental stages in alfalfa. Theor. Appl. Genet. 83:833-838 https://doi.org/10.1007/BF00226705

Lai Y, Cheng J, He Y et al (2016) Identification of QTLs with Additive, Epistatic, and QTL $\times$ Seed Maturity Interaction Effects for Seed Vigor in Rice. Plant Mol Biol Report. 34(1):160-171. https://doi.org/10.1007/s11105-015-0913-7

Lander ES, Green P, Abrahamson J et al (1987) MAPMAKER: An interactive computer package for constructing primary genetic linkage maps of experimental and natural populations. Genomics 1: 174- 
Li H, Ribaut JM, Li Z et al (2008) Inclusive composite interval mapping (ICIM) for digenic epistasis of quantitative traits in biparental populations. Theor Appl Genet 116(2):243-260. https://doi.org/10.1007/s00122-007-0663-5

Li Y, Fan C, Xing Y et al (2011) Natural variation in GS5 plays an important role in regulating grain size and yield in rice. Nat Genet 43:1266-1269. https://doi.org/10.1038/ng.977

Livak KJ, Schmittgen TD (2001) Analysis of relative gene expression data using real-time quantitative PCR and the $2^{-\triangle \Delta C T}$ method. Methods 25(4):402-408. https://doi.org/10.1006/meth.2001.1262

McCouch SR, Teytelman L, Xu Y et al (2002) Development and mapping of 2240 new SSR markers for rice (Oryza sativa L.). DNA Res 9(6):199-207. https://doi.org/10.1093/dnares/9.6.199

Michelmore RW, Paran I, Kesseli RV (1991) Identification of markers linked to disease-resistance genes by bulked segregant analysis: A rapid method to detect markers in specific genomic regions by using segregating populations. Proc Natl Acad Sci U S A 88(21):9828-9832.

https://doi.org/10.1073/pnas.88.21.9828

Munns R, Gilliham M (2015) Salinity tolerance of crops - what is the cost? New Phytol. 208: 668-673. https://doi.org/10.1111/nph.13519

Munns R, Tester M (2008) Mechanisms of salinity tolerance. Annu Rev Plant Biol 59:651-681. https://doi.org/10.1146/annurev.arplant.59.032607.092911

Ren ZH, Gao JP, Li LG et al (2005) A rice quantitative trait locus for salt tolerance encodes a sodium transporter. Nat Genet 37:1141-1146. https://doi.org/10.1038/ng1643

Salunkhe AS, Poornima R, Prince KSJ et al (2011) Fine mapping QTL for drought resistance traits in rice (Oryza sativa L.) using bulk segregant analysis. Mol Biotechnol 49:90-95 https://doi.org/10.1007/s12033-011-9382-x

Shi Y, Gao L, Wu Z et al (2017) Genome-wide association study of salt tolerance at the seed germination stage in rice. BMC Plant Biol 17:92. https://doi.org/10.1186/s12870-017-1044-0

Stoker AW (2005) Protein tyrosine phosphatases and signalling. J. Endocrinol.

Takehisa $\mathrm{H}$, Shimodate T, Fukuta $\mathrm{Y}$, et al (2004) Identification of quantitative trait loci for plant growth of rice in paddy field flooded with salt water. Field Crop Res 89: 85-95.

Takagi H, Tamiru M, Abe A et al (2015) MutMap accelerates breeding of a salt-tolerant rice cultivar. Nat Biotechnol 33:445-449. https://doi.org/10.1038/nbt.3188 
Tiwari S, SL K, Kumar V et al (2016) Mapping QTLs for salt tolerance in rice (Oryza sativa L.) by bulked segregant analysis of recombinant inbred lines using 50K SNP chip. PLoS One 11(4): e0153610. https://doi.org/10.1371/journal.pone.0153610

Vikram P, Swamy BPM, Dixit S et al (2012) Bulk segregant analysis: "An effective approach for mapping consistent-effect drought grain yield QTLs in rice." F Crop Res 134:185-192.

https://doi.org/10.1016/j.fcr.2012.05.012

Wang Z, Chen Z, Cheng J et al (2012a) QTL analysis of $\mathrm{Na}^{+}$and $\mathrm{K}^{+}$concentrations in roots and shoots under different levels of $\mathrm{NaCl}$ stress in rice (Oryza sativa L.). PLoS One 7(12): e51202.

https://doi.org/10.1371/journal.pone.0051202

Wang Z, Cheng J, Chen Z et al (2012b) Identification of QTLs with main, epistatic and QTL × environment interaction effects for salt tolerance in rice seedlings under different salinity conditions. Theor Appl Genet 125:807-815. https://doi.org/10.1007/s00122-012-1873-z

Wang Z, Wang J, Bao Y et al (2011) Quantitative trait loci controlling rice seed germination under salt stress. Euphytica 178(3):297-307. https://doi.org/10.1007/s10681-010-0287-8

Xu Q, Fu HH, Gupta R et al (1998) Molecular characterization of a tyrosine-specific protein phosphatase encoded by a stress-responsive gene in Arabidopsis. Plant Cell 10: 849-857.

https://doi.org/10.1105/tpc.10.5.849

Yu J, Zhao W, Tong W et al (2018) A genome-wide association study reveals candidate genes related to salt tolerance in rice (Oryza sativa) at the germination stage. Int J Mol Sci 19(10):3145. https://doi.org/10.3390/ijms19103145

Zhang X, Wang J, Huang $\mathrm{J}$ et al (2012) Rare allele of OSPPKL 1 associated with grain length causes extralarge grain and a significant yield increase in rice. Proc Natl Acad Sci U S A 109(52):21534-21539. https://doi.org/10.1073/pnas.1219776110

Zheng $\mathrm{H}$, Zhao H, Liu H et al (2015) QTL analysis of $\mathrm{Na}^{+}$and $\mathrm{K}^{+}$concentrations in shoots and roots under $\mathrm{NaCl}$ stress based on linkage and association analysis in japonica rice. Euphytica 201:109-121. https://doi.org/10.1007/s10681-014-1192-3

Zhu JK (2001) Plant salt tolerance. Trends Plant Sci 6(2):66-71. https://doi.org/10.1016/S13601385(00)01838-0

\section{Tables}

Table 1 Dynamic QTLs identified using BC1F2 population at $300 \mathrm{mM} \mathrm{NaCl}$ during seed germination 


\begin{tabular}{|c|c|c|c|c|c|c|c|c|c|}
\hline Traits & QTLs & Days & Chr. & $\begin{array}{c}\text { Left } \\
\text { Marker }\end{array}$ & $\begin{array}{c}\text { Right } \\
\text { Marker }\end{array}$ & $\mathrm{LOD}^{\mathrm{a}}$ & $\begin{array}{c}\mathrm{PVE}^{\mathrm{b}} \\
(\%)\end{array}$ & $\mathrm{Add}^{\mathrm{C}}$ & $\operatorname{Dom}^{\mathrm{d}}$ \\
\hline \multirow[t]{28}{*}{ GR } & $q G R 1$ & $4 d$ & 1 & RM8105 & Y3 & 11.75 & 72.22 & -8.82 & -9.44 \\
\hline & \multirow{4}{*}{$q G R 6.1$} & $11 d$ & 6 & RM190 & Z602 & 2.57 & 6.46 & -6.34 & 5.89 \\
\hline & & $12 d$ & 6 & RM190 & Z602 & 3.00 & 7.36 & -6.16 & 5.62 \\
\hline & & $13 d$ & 6 & RM190 & Z602 & 3.20 & 6.89 & -5.31 & 4.37 \\
\hline & & $14 d$ & 6 & RM190 & Z602 & 3.28 & 6.91 & -5.00 & 3.37 \\
\hline & \multirow[t]{8}{*}{$q G R 6.2$} & $7 d$ & 6 & Z604 & RM276 & 9.19 & 21.59 & -1.45 & -20.07 \\
\hline & & $8 d$ & 6 & Z604 & RM276 & 10.88 & 24.94 & -0.68 & -21.13 \\
\hline & & $9 d$ & 6 & Z604 & RM276 & 11.19 & 25.99 & -0.78 & -19.98 \\
\hline & & $10 \mathrm{~d}$ & 6 & Z604 & RM276 & 11.09 & 25.59 & -0.47 & -18.51 \\
\hline & & $11 d$ & 6 & Z604 & RM276 & 10.46 & 23.98 & -0.79 & -16.48 \\
\hline & & $12 d$ & 6 & Z604 & RM276 & 10.73 & 24.60 & -0.50 & -15.22 \\
\hline & & $13 d$ & 6 & Z604 & RM276 & 11.11 & 25.38 & -0.82 & -13.51 \\
\hline & & $14 d$ & 6 & Z604 & RM276 & 10.72 & 24.10 & -0.99 & -11.84 \\
\hline & $q G R 6.3$ & $5 d$ & 6 & RM276 & RM7088 & 2.69 & 9.64 & -5.10 & -6.12 \\
\hline & \multirow[t]{3}{*}{$q G R 8$} & $4 d$ & 8 & RM3572 & RM6208 & 3.10 & 7.77 & -1.73 & -2.41 \\
\hline & & $5 d$ & 8 & RM3572 & RM6208 & 3.72 & 21.18 & -8.50 & -8.72 \\
\hline & & $6 d$ & 8 & RM3572 & RM6208 & 6.73 & 18.21 & -5.70 & -14.58 \\
\hline & \multirow[t]{11}{*}{$q G R 10$} & $4 d$ & 10 & W13 & W20 & 3.34 & 10.93 & -2.90 & -2.24 \\
\hline & & $5 d$ & 10 & W13 & W20 & 3.79 & 12.70 & -7.86 & -4.25 \\
\hline & & $6 d$ & 10 & W13 & W20 & 5.21 & 14.70 & -11.22 & 0.09 \\
\hline & & $7 d$ & 10 & W13 & W20 & 6.30 & 16.76 & -12.13 & 2.92 \\
\hline & & $8 d$ & 10 & W13 & W20 & 7.45 & 18.73 & -12.13 & 3.87 \\
\hline & & $9 d$ & 10 & W13 & W20 & 7.25 & 17.86 & -11.11 & 3.30 \\
\hline & & $10 \mathrm{~d}$ & 10 & W13 & W20 & 7.78 & 19.09 & -10.49 & 3.9 \\
\hline & & $11 d$ & 10 & W13 & W20 & 7.74 & 19.51 & -9.83 & 4.14 \\
\hline & & $12 d$ & 10 & W13 & W20 & 7.48 & 18.75 & -8.65 & 3.86 \\
\hline & & $13 d$ & 10 & W13 & W20 & 7.15 & 17.52 & -7.46 & 3.26 \\
\hline & & $14 d$ & 10 & W13 & W20 & 7.52 & 17.62 & -6.94 & 2.70 \\
\hline \multirow[t]{16}{*}{ SP } & $q S P 1$ & $8 d$ & 1 & RM8105 & Y3 & 5.46 & 62.27 & -11.17 & -12.73 \\
\hline & \multirow[t]{3}{*}{$q S P 6.1$} & $10 \mathrm{~d}$ & 6 & Z604 & RM276 & 5.61 & 13.02 & -4.89 & -11.03 \\
\hline & & $13 d$ & 6 & Z604 & RM276 & 7.71 & 17.84 & -2.85 & -15.70 \\
\hline & & $14 d$ & 6 & Z604 & RM276 & 8.43 & 19.62 & -1.65 & -15.80 \\
\hline & \multirow[t]{2}{*}{$q S P 6.2$} & $9 d$ & 6 & RM276 & RM7088 & 3.64 & 20.83 & -7.43 & -9.15 \\
\hline & & $11 d$ & 6 & RM276 & RM7088 & 7.00 & 24.60 & -8.99 & -16.16 \\
\hline & $q S P 7$ & $14 \mathrm{~d}$ & 7 & RM18 & RM5426 & 2.62 & 4.90 & -5.92 & 1.1604 \\
\hline & \multirow[t]{2}{*}{$q S P 8.1$} & $9 d$ & 8 & RM3572 & RM6208 & 2.98 & 9.37 & -4.45 & -6.23 \\
\hline & & $12 d$ & 8 & RM3572 & RM6208 & 6.65 & 18.55 & -6.72 & -14.60 \\
\hline & qSP8.2 & $7 d$ & 8 & RM1345 & RM6070 & 2.84 & 7.04 & -1.24 & -0.99 \\
\hline & \multirow[t]{5}{*}{$q S P 10.1$} & $10 \mathrm{~d}$ & 10 & W13 & W20 & 5.60 & 16.49 & -10.81 & 4.18 \\
\hline & & $11 d$ & 10 & W13 & W20 & 5.94 & 17.15 & -12.07 & 4.98 \\
\hline & & $12 d$ & 10 & W13 & W20 & 5.45 & 15.97 & -11.37 & 5.59 \\
\hline & & $13 d$ & 10 & W13 & W20 & 7.30 & 20.13 & -11.42 & 6.95 \\
\hline & & $14 d$ & 10 & W13 & W20 & 7.83 & 21.48 & -10.48 & 7.18 \\
\hline & $q S P 10.2$ & $9 d$ & 10 & W20 & RM6824 & 2.98 & 8.10 & -5.52 & 5.03 \\
\hline
\end{tabular}


Table 2 Molecular markers linked with salt tolerance during seed germination

\begin{tabular}{cccc}
\hline \multicolumn{3}{c}{ SSR Markers Chr. Physical Position(Mb) } & QTLs identified in $\mathrm{BC}_{1} \mathrm{~F}_{2}$ \\
\hline RM128 & 1 & 32.494618 & \\
RM1164 & 3 & 15.412771 & \\
\hline RM3436 & 3 & 28.182746 & \\
RM3564 & 3 & 34.282475 & \\
RM3684 & 3 & 35.474139 & \\
RM317 & 4 & 29.644750 & $q G R 6.1$ \\
RM480 & 5 & 27.457680 & $q G R 6.1$ \\
RM588 & 6 & 1.611417 & \\
RM190 & 6 & 1.764657 & $q S P 8.2$ \\
RM276 & 6 & 6.230150 & $q G R 6.2, q G R 6.3, q S P 6.1, q S P 6.2$ and $q G I 6$ \\
\hline RM6818 & 6 & 17.459525 & \\
RM5493 & 8 & 26.236335 & \\
\hline
\end{tabular}

Table 3 The predicted candidate genes in the $q G R 6.2$ region

\begin{tabular}{|c|c|c|}
\hline Number & Candidate genes & Putative protein function \\
\hline ORF1 & LOC_Os06g10650 & Tyrosine phosphatase family protein, putative, expressed \\
\hline ORF2 & LOC_Os06g10660 & $\begin{array}{l}\text { LysM domain-containing GPI-anchored protein } 1 \text { precursor, } \\
\text { putative, expressed }\end{array}$ \\
\hline ORF3 & LOC_Os06g10670 & $\begin{array}{l}\text { Aspartic proteinase nepenthesin-1 precursor, putative, } \\
\text { expressed }\end{array}$ \\
\hline ORF4 & LOC Os06g10680 & Expressed protein \\
\hline ORF5 & LOC_Os06g 10690 & PHD-finger domain containing protein, putative, expressed \\
\hline ORFG & LOC_Os06g10700 & Expressed protein \\
\hline ORF7 & LOC_Os06g10710 & Expressed protein \\
\hline ORF8 & LOC_Os06g10720 & Expressed protein \\
\hline ORF9 & LOC_Os06g10730 & Expressed protein \\
\hline ORF10 & LOC_Os06g10740 & Transposon protein, putative, unclassified, expressed \\
\hline ORF11 & LOC_Os06g10750 & $\begin{array}{l}\text { Integral membrane protein DUF6 containing protein, } \\
\text { expressed }\end{array}$ \\
\hline
\end{tabular}

\section{Figures}


a

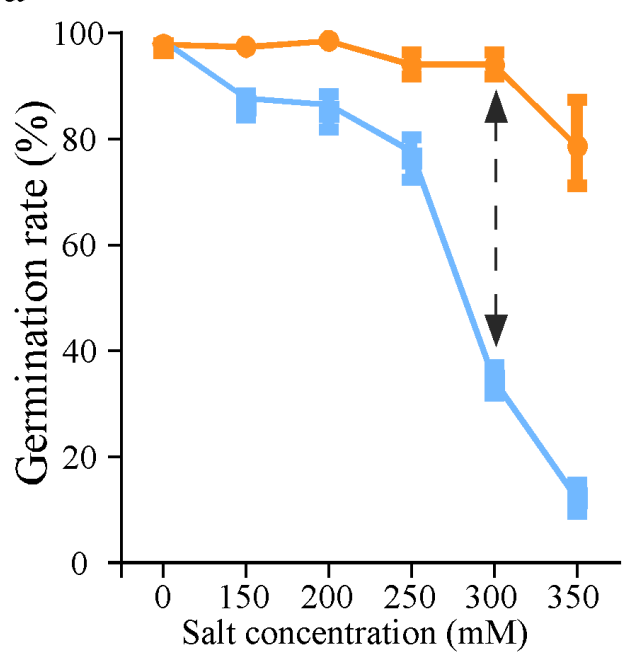

c

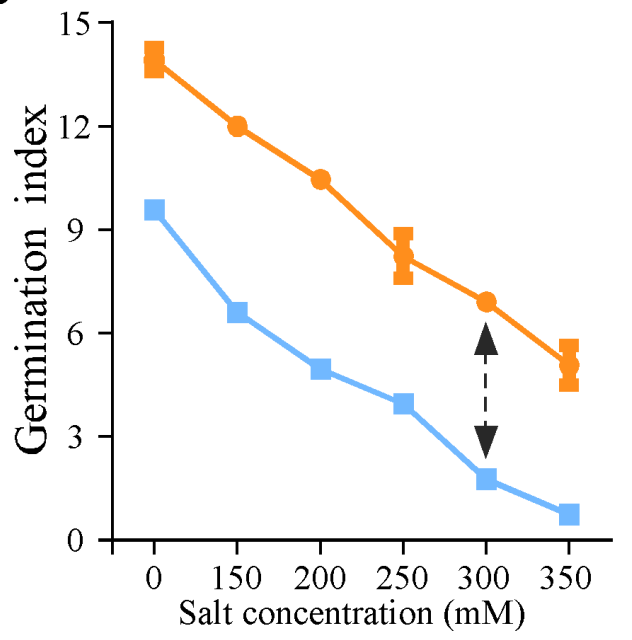

b

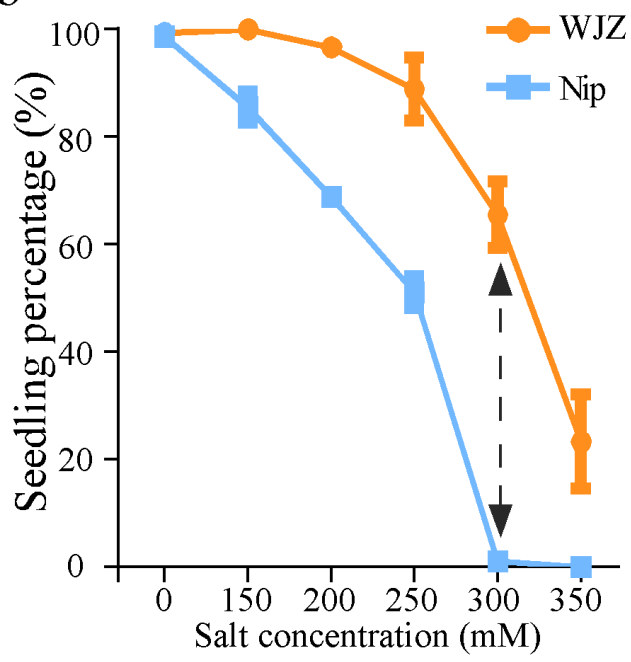

d

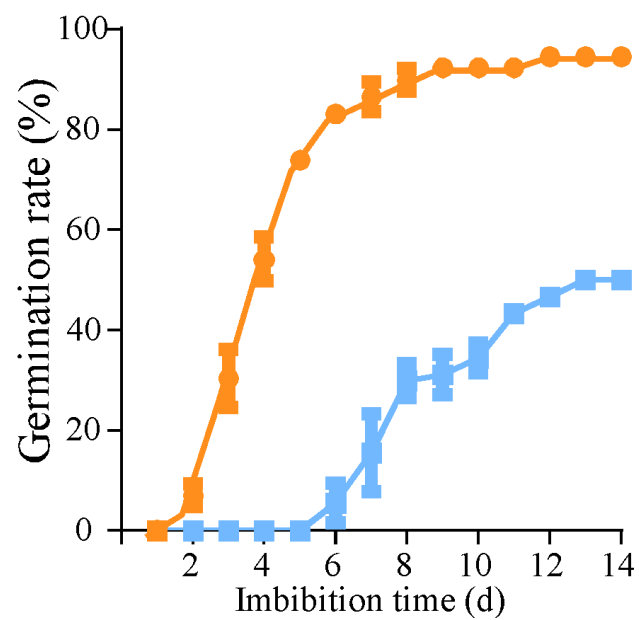

e

$3 d$
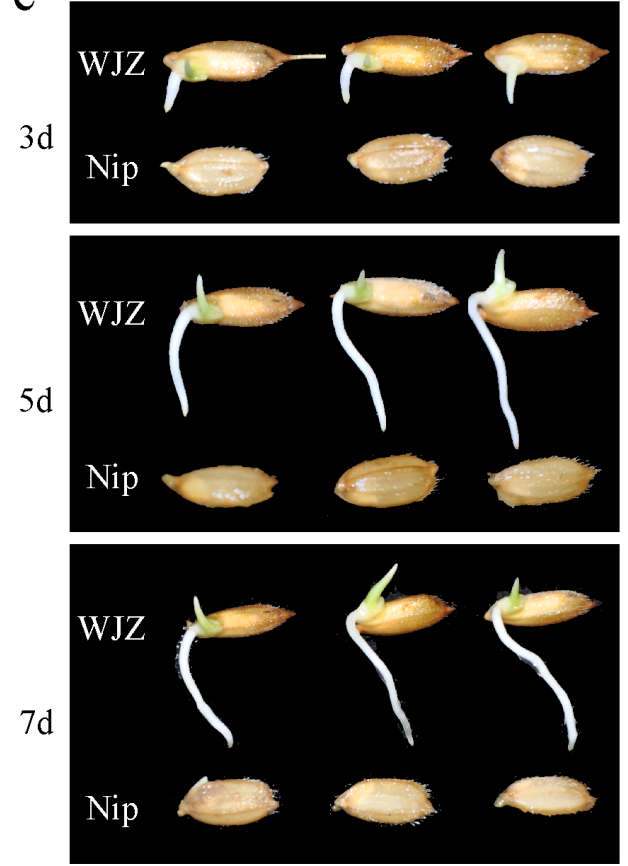

$9 d$

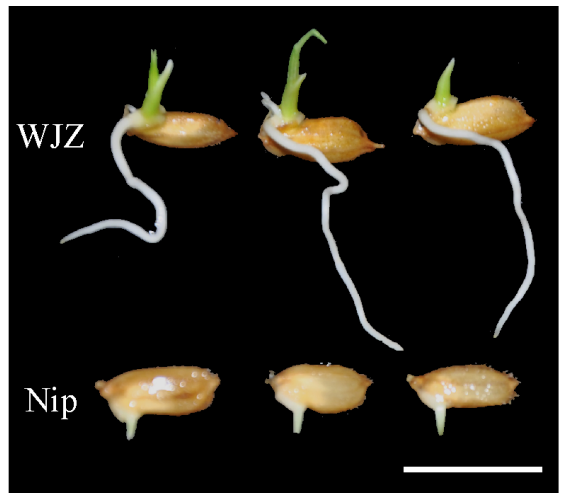

\section{Figure 1}

Salt tolerance evaluation of seed germination and seedling establishment between Wujiaozhan (WJZ) and Nipponbare (Nip). (a-d) Quantification and statistical analysis of germination rate of $10 \mathrm{~d}(\mathrm{a})$, seedling percentage of $10 \mathrm{~d}$ (b), and germination index (c) of two varieties under different concentrations of $\mathrm{NaCl}$. (d) Quantification of germination rate from 1 to 14 days in two parent varieties at $300 \mathrm{mM} \mathrm{NaCl}$. Each point represents the means \pm standard deviation. (e) Morphology of two varieties during seed germination after 3, 5, 7 and 9 days at $300 \mathrm{mM} \mathrm{NaCl}$. Scale bar $=1 \mathrm{~cm}$. The arrows in a-c indicate the large variation between WJZ and Nip at $300 \mathrm{mM} \mathrm{NaCl}$. 


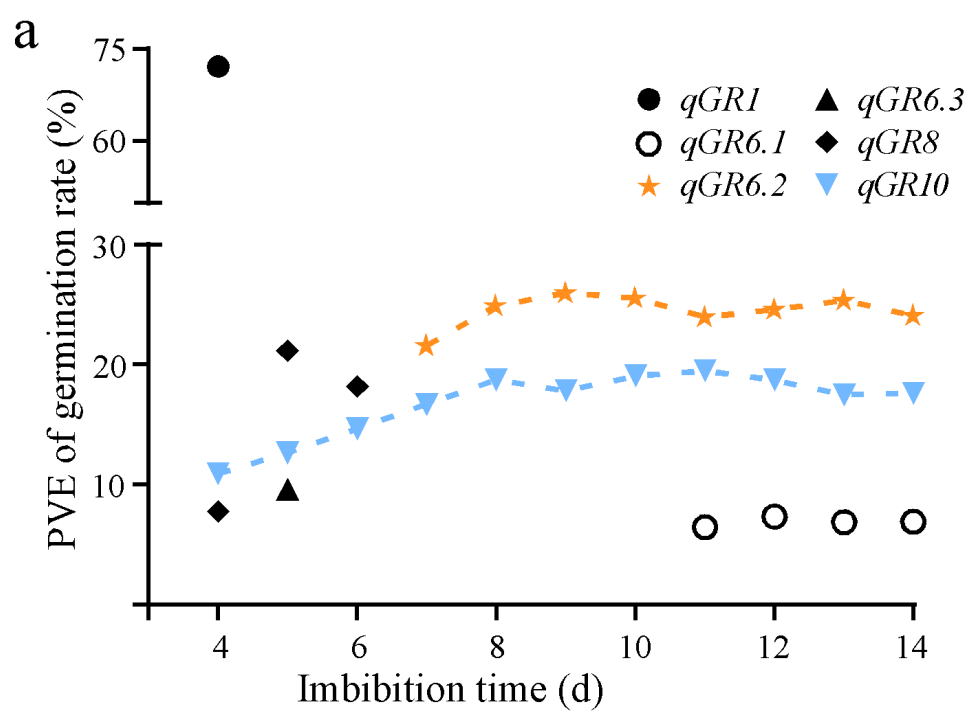

b

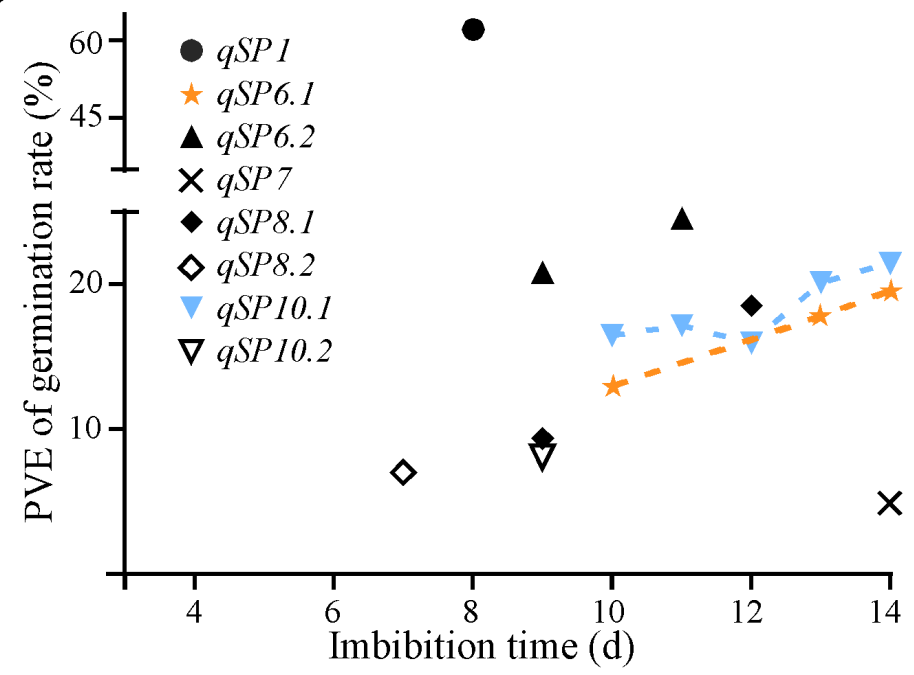

Figure 2

Dynamic putative QTLs controlling germination rate and seedling percentage detected from the BC1F2 population. (a) QTLs of germination rate. (b) QTLs of seedling percentage.
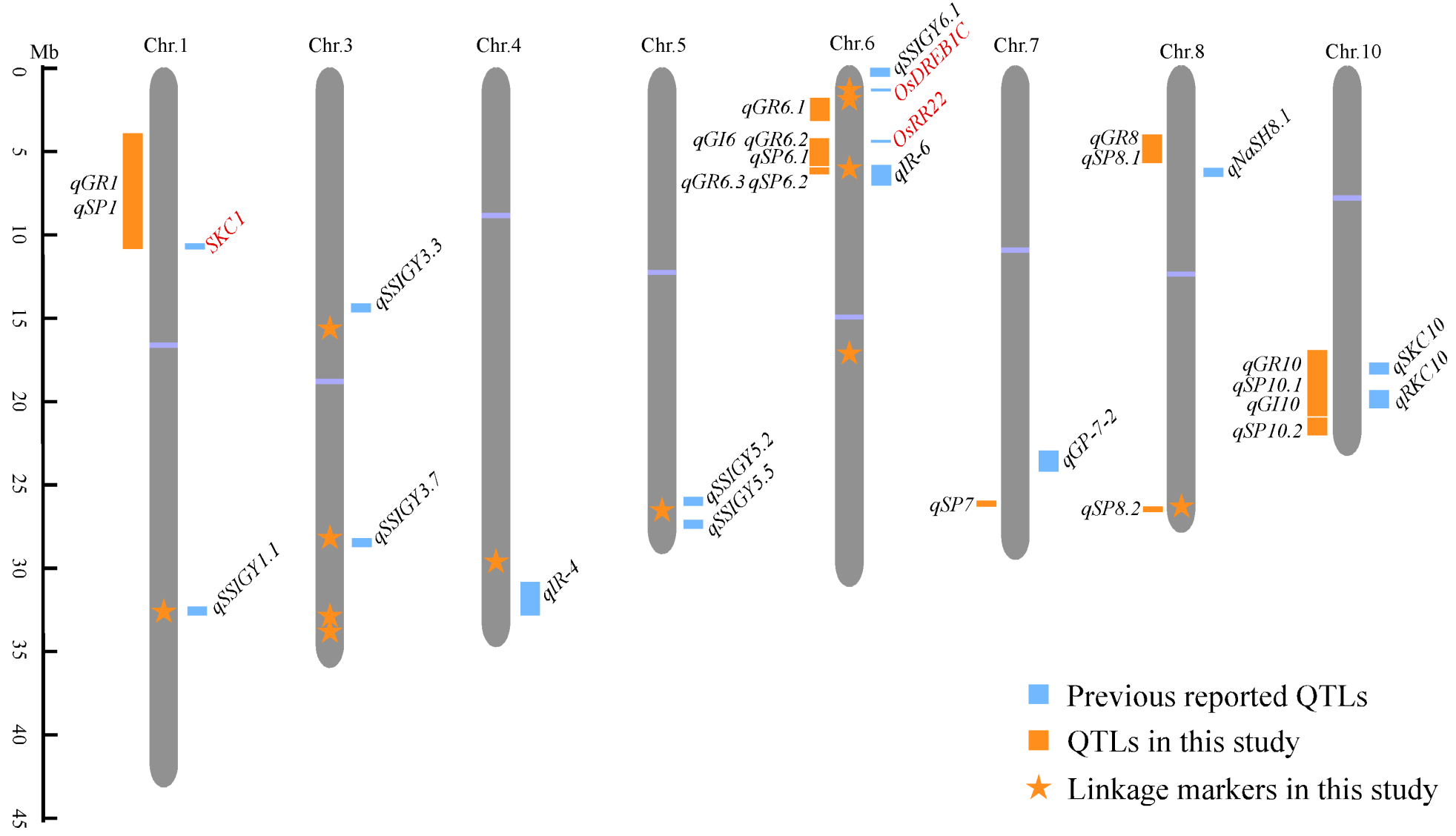

Figure 3

The co-located putative QTLs and associated physical locus in this study compared with previously mapped QTLs of salt tolerance in rice. The main associated QTLs from this study are shown on the left (orange frame and pentagram) and previously identified QTLs for salt tolerance are shown on the right 
(blue frame) (Dubouzet et al. 2003; Wang et al. 2011; Wang et al. 2012; Wang et al. 2012; Vinod et al. 2015; Sushma et al. 2016; Shi et al. 2017; Yu et al. 2018).

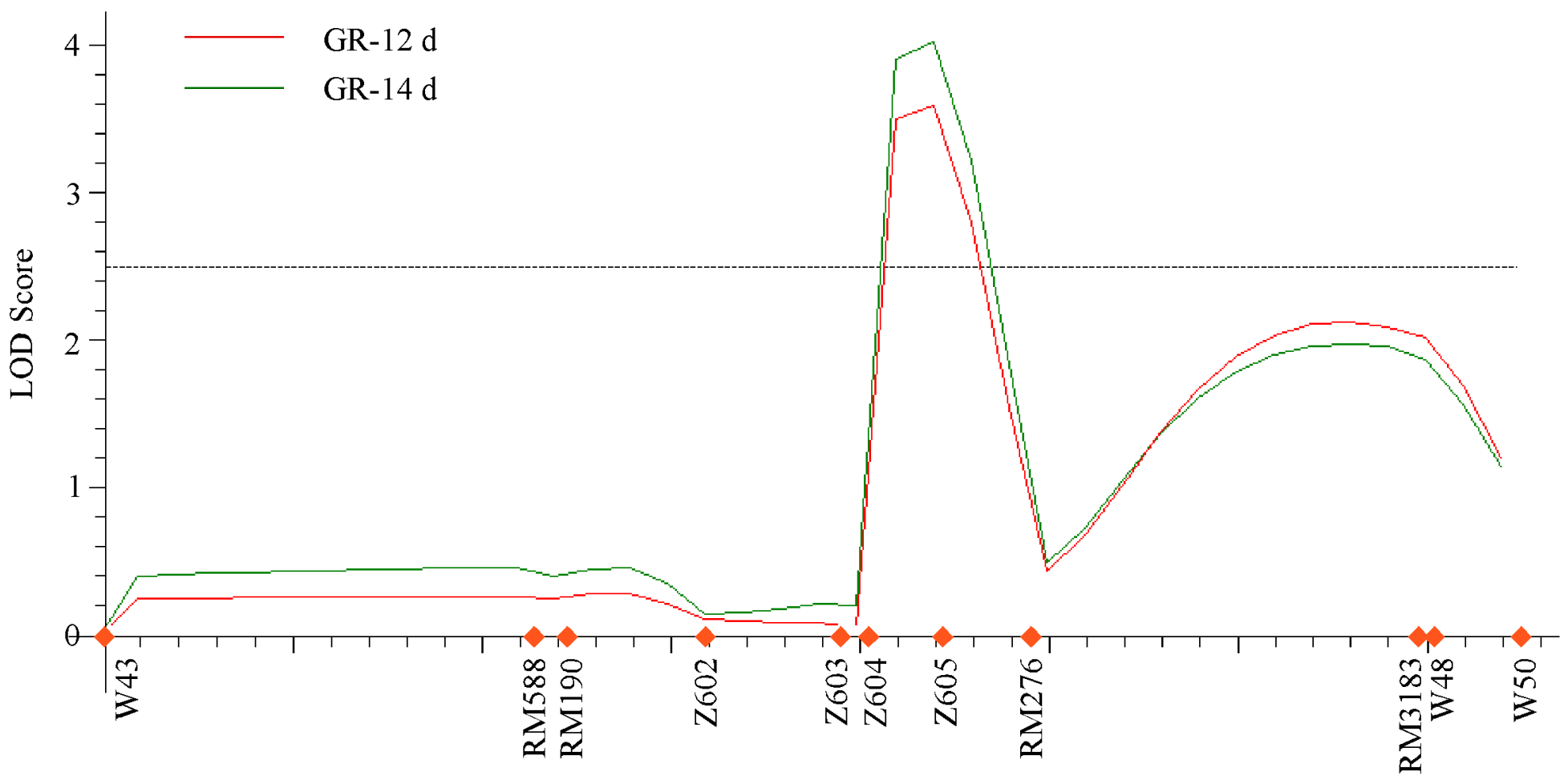

Figure 4

LOD score curves for the qGR6.2 controlling seed germination rate at 12th and 14th days in the BC2F2 population. The LOD curve indicates the strength of evidence for the presence of qGR6.2 within Z64RM276 on chromosome 6. Dashed lines show LOD thresholds of 2.50. Marker names and genetic distances are shown below the chromosome. 
a

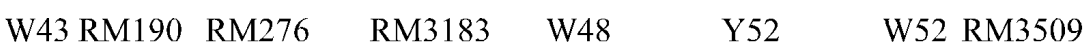

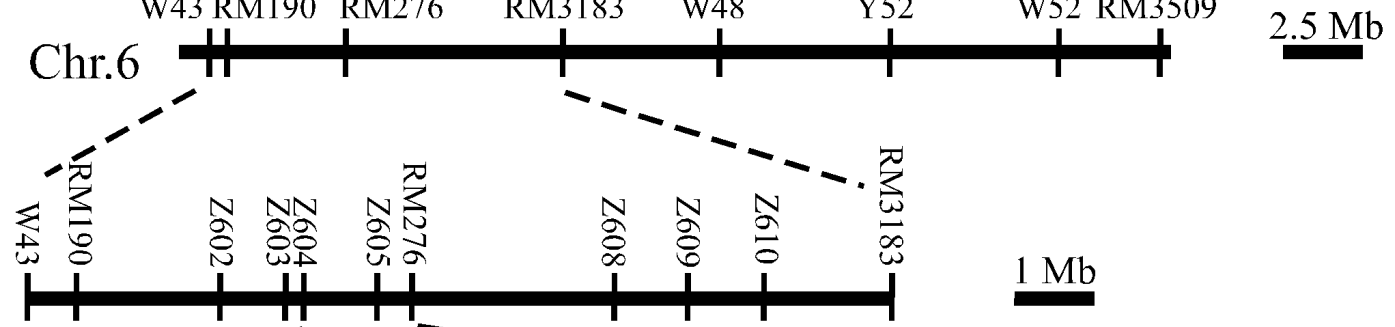

b

$(\mathrm{n}=1205)$

(A)

(B)

(C)

(D)

C

$(\mathrm{n}=2318)$

(E)

(F)

(G)

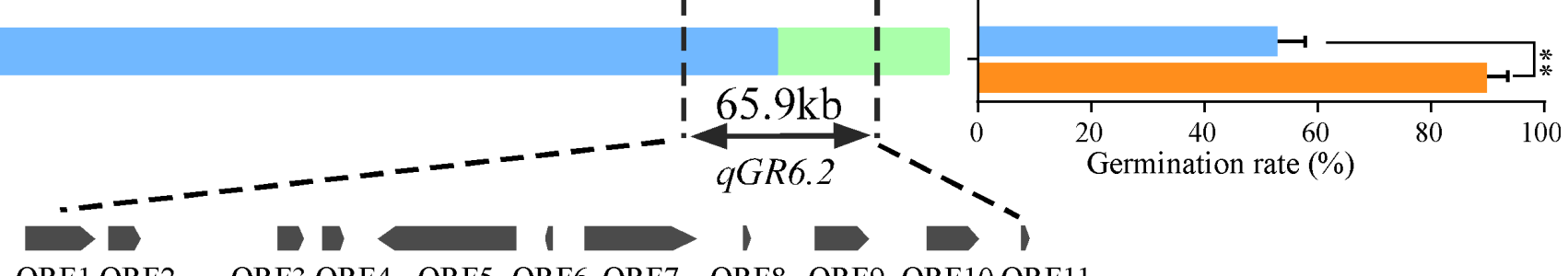

(18)

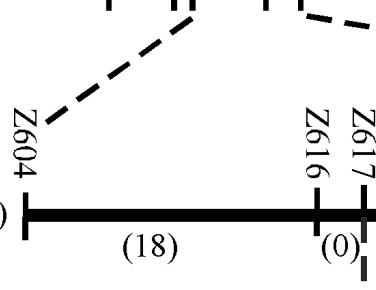

(57)

$(0)$

(11)

$125 \mathrm{~Kb}$

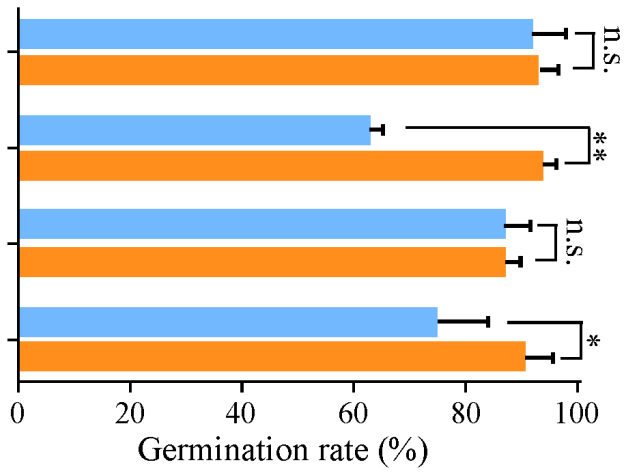

$25 \mathrm{~Kb}$

(5)

(0)

(12)
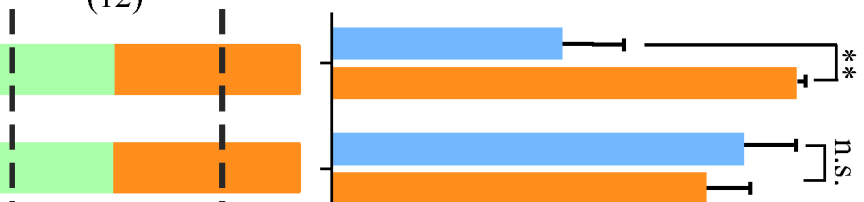

Germination rate $(\%)$

WJZ

Nip

Heterozygote 
Percent of Expression Potential

Stage of development
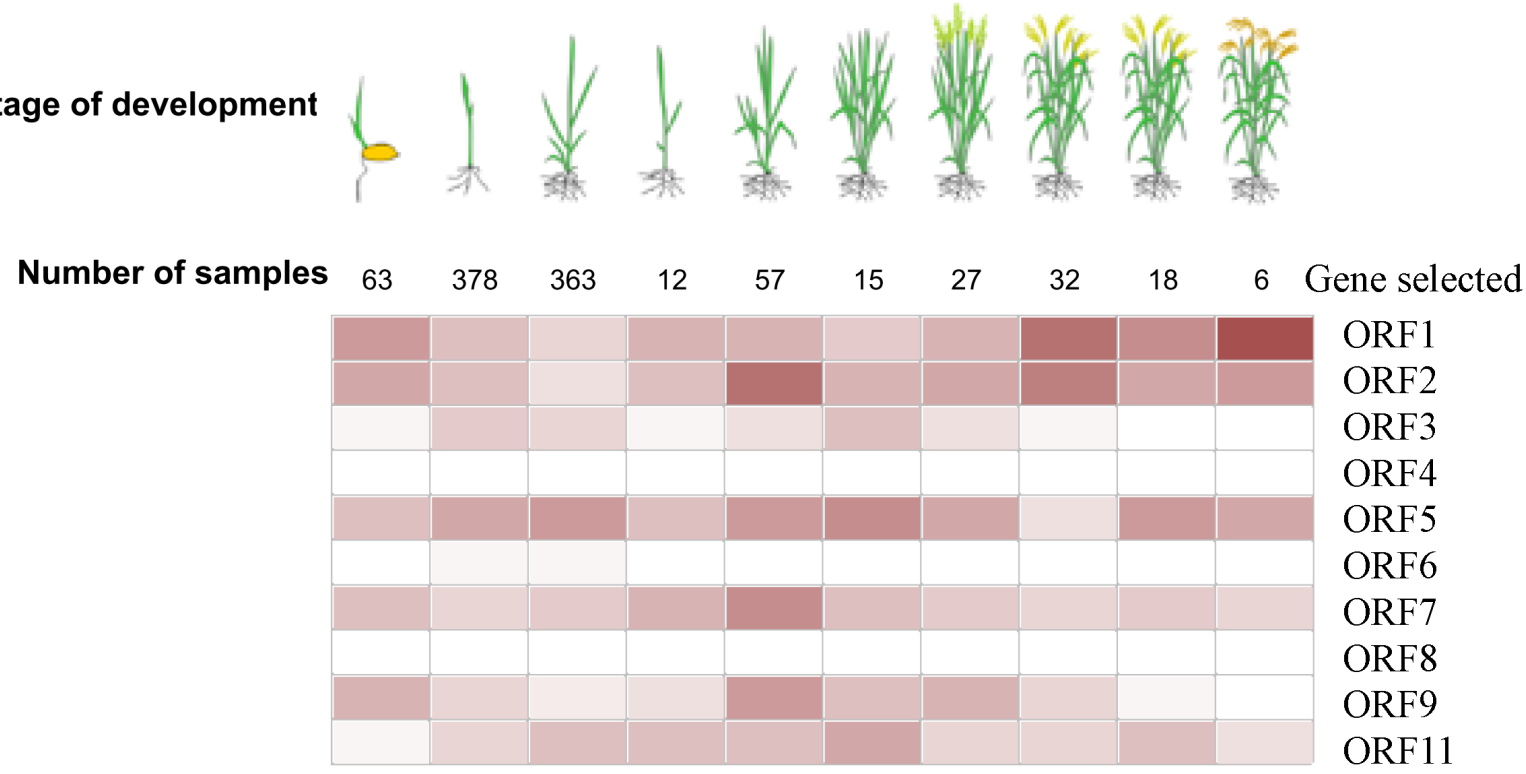

b

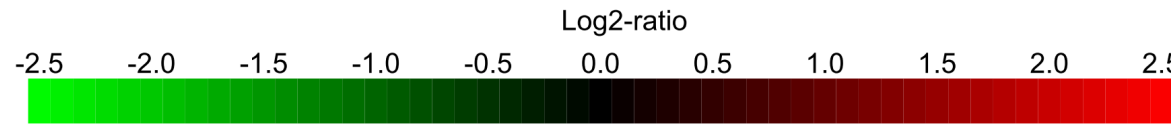

Down-regulated

Up-regulated

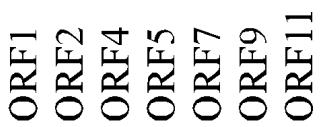

OS-00052 imbibition (24h) / embryo samples from dry seeds

OS-00108 imbibition (12h; embryo) / embryo samples from dry seeds

OS-00108 imbibition (16h; embryo) / embryo samples from dry seeds

OS-00108 imbibition (24h; embryo) / embryo samples from dry seeds

OS-00052 imbibition (12h) / embryo samples from dry seeds

OS-00108 imbibition (8h; embryo) / embryo samples from dry seeds

OS-00052 imbibition (24h) / imbibition (1h)

OS-00052 imbibition (12h) / imbibition (1h)

OS-00108 imbibition (4h; embryo) / embryo samples from dry seeds

OS-00052 imbibition (3h) / embryo samples from dry seeds

OS-00052 imbibition (3h) / imbibition (1h)

OS-00052 imbibition (1h) / embryo samples from dry seeds

OS-00032 salt tolerant RILs / salt sensitive RILs

OS-00221 salt (IR64; ABA; root) / salt (IR64; root)

OS-00221 salt (IR64; ABA; root) / untreated root samples (IR64)

OS-00221 salt (PL177; ABA; root) / untreated root samples (PL177)

OS-00032 salt (salt sensitive RILs) / untreated seedling samples (salt sensitive RILs)

OS-00032 salt (salt tolerant RILs) / untreated seedling samples (salt tolerant RILs)

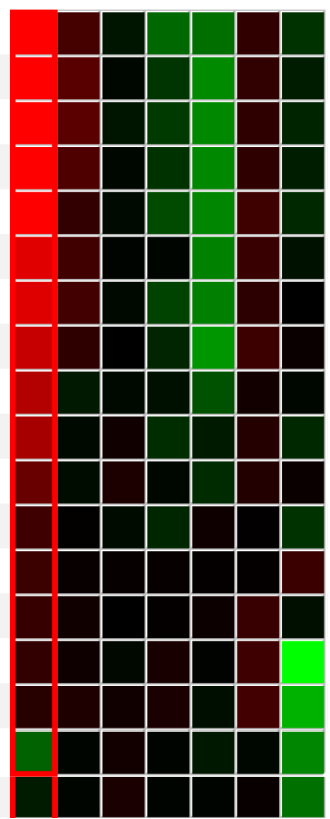

\section{Figure 6}

Expression pattern of candidate genes in various developmental stages (a) and response to seed germination and salt stress (b) based on Affymetrix microarray datasets and mRNASeq data from the GENEVESTIGATOR (http://www.genevestigator.com). 
a

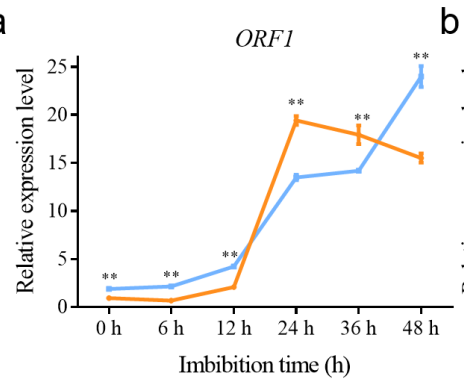

e

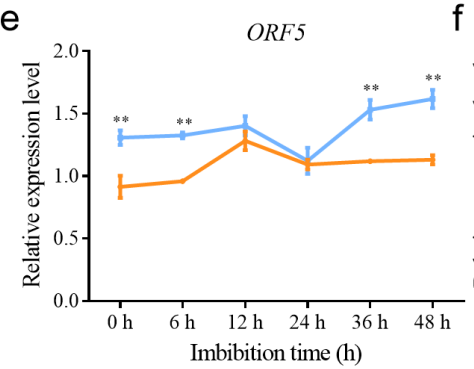

i

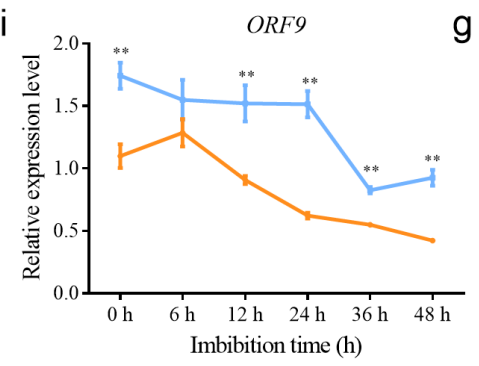

b

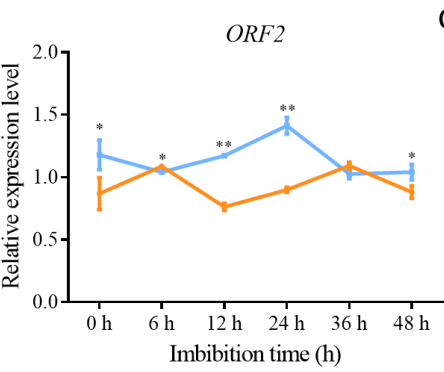

$f$

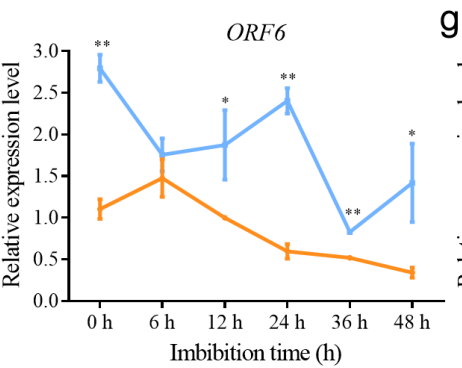

g

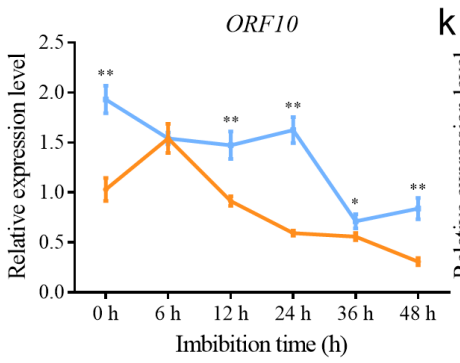

C
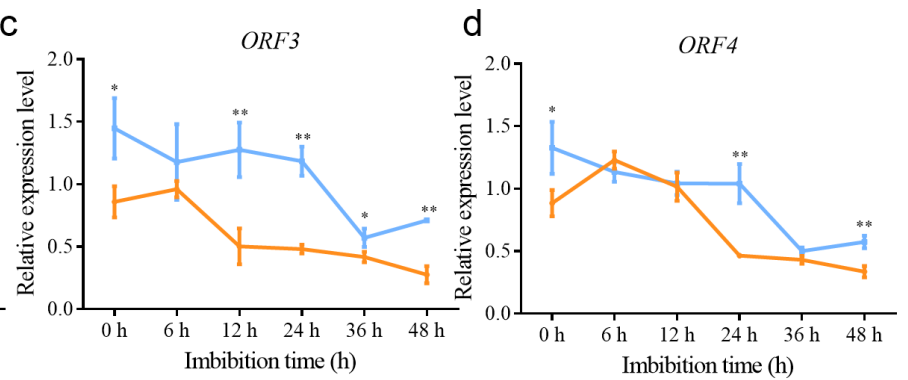

g $\mathrm{h}$

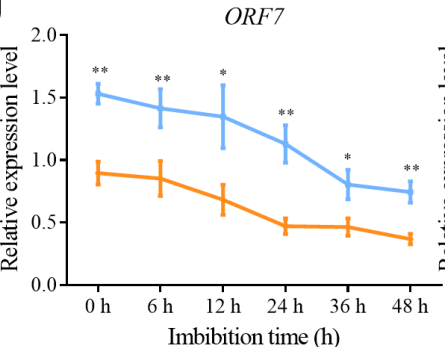

h ORF8

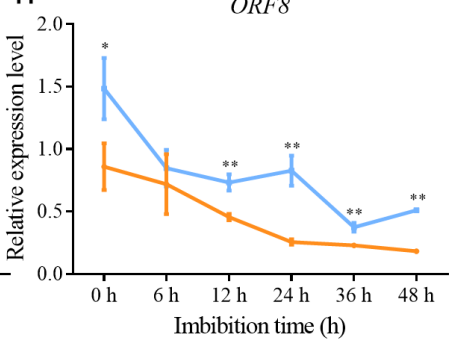

ORF 11

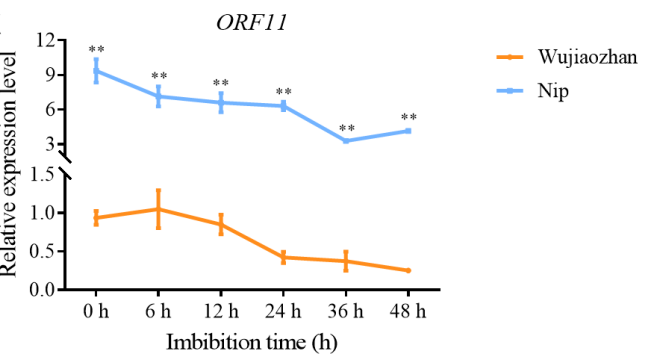

\section{Figure 7}

Expression levels of candidate genes regulated by WJZ and Nip during seed germination at $300 \mathrm{mM}$ $\mathrm{NaCl}$.

\section{Supplementary Files}

This is a list of supplementary files associated with this preprint. Click to download.

- FigS4.tif

- FigS3.tif

- FigS1.tif

- Supplementarytable.xlsx

- Figs2.tif 